Management of bleomycin lung toxicity is frequently difficult, though steroids are widely recommended and evidence supporting their role comes from both animal studies $^{6}$ and clinical reports on a few patients. ${ }^{5}$

Less settled, however, is the value of these agents in advanced bleomycin lung toxicity. Samuels and coworkers ${ }^{7}$ described a series of five such patients, all of whom received prednisolone in doses of $60-100 \mathrm{mg}$ daily. All five died of acute respiratory failure despite this treatment. Gilson and $\mathrm{Sahn}^{8}$ reported a patient with bleomycin lung toxicity who developed the adult respiratory distress syndrome after surgery and ultimately responded to a combination of antibiotics and methylprednisolone $500 \mathrm{mg}$ a day. Recently Hartmann and colleagues ${ }^{9}$ also described a patient with life threatening bleomycin lung toxicity successfully treated with methylprednisolone $1 \mathrm{~g}$ daily. Our case, taken in conjunction with these, suggests that severe bleomycin lung toxicity may be largely reversible provided that the treatment regimen incorporates corticosteroids in very high doses that are tapered gradually. We elected to use azathioprine in addition because of its immunosuppressive and known steroid sparing effects.

We believe that all patients with bleomycin lung toxicity should receive a trial of corticosteroids. The dose used should depend on the severity of the pneumonitis.

1 Umezawa H, Maeda K, Takeuchi T, Okami Y. New antibiotics, bleomycin A and B. Fournal of Antibiotics (Tokyo) 1966;19:200-9.

2 Kuo MT, Haidle CW. Characterization of chain breakage in DNA induced by bleomycin. Biochem Biophys Acta 1974;335:109-14.

3 Chandler DB. Possible mechanisms of bleomycin-induced fibrosis. In: Cooper J Allen D, ed. Clinics in chest medicine. Philadelphia: Saunders, 1990:21-30.

4 Holoye PY, Luna MA, Mackay B, Bedrossian CWM. Bleomycin hypersensitivity pneumonitis. Ann Intern Med Bleomycin hypers

5 Jules-Elysee K, White DA. Bleomycin-induced pulmonary toxicity. In: Cooper J Allen D, ed. Clinics in chest medicine. Philadelphia: Saunders, 1990:1-20

6 Sterling KM, Di Petrillo T, Cutroneo KR, Perstayko A Inhibition of collagen accumulation by glucocorticoids in rat lung after intratracheal bleomycin instillation. Cancer Res 1982;42:405-8.

7 Samuels ML, Johnson DE, Holoye PY, Lanzotti VJ. Large dose bleomycin therapy and pulmonary toxicity: a possible role of prior radiotherapy. $\Im A M A$ 1976;235: possible role.

8 Gilson AJ, Sahn SA. Reactivation of bleomycin lung toxicity following oxygen administration. Chest 1985;88: 304-6.

9 Hartmann LC, Frytak S, Richardson RL, Coles DT, Cupps RE. Life-threatening bleomycin pulmonary toxicity with ultimate reversibility. Chest 1990;98:497-9.

Thorax 1993;48:94-95

\section{Pseudomyxoma of the pleural and peritoneal cavities}

G Radosavljević, B Nedeljković, V Kačar

\begin{abstract}
Pseudomyxoma peritonei is a rare clinical manifestation of mucin producing adenocarcinomas. An extensively metastased adenocarcinoma developed a pseudomyxoma that affected not only the peritoneal cavity but also the pleura.
\end{abstract}

(Thorax 1993;48:94-95)

Pseudomyxoma peritonei is a rare clinical entity characterised by mucinous tumour masses in the peritoneum and omentum with gelatinous ascites. It usually originates from adenocarcinoma of the appendix or ovary and less frequently from adenocarcinoma of other organs. ${ }^{1-4}$

We present a patient with pseudomyxoma that affected not only the peritoneum but also the pleura.

Diseases and

Tuberculosis,

University Clinical

Centre, 11000

Belgrade, Višegradska

26, 11000 Belgrade,

Serbia

G Radosavljević

B Nedeliković

V Kačar

Reprint requests to: Dr G Radosavljević

Received 21 October 1991

Returned to authors

Revised version received

23 January 1992

Accepted 28 January 1992

\section{Case report}

A 41 year old farmer, a non-smoker, was admitted to hospital in December 1988 because of mild chest pain and breathlessness, clinical signs of ascites, and homogeneous shadowing in the left hemithorax on the chest radiograph (fig 1). His general condition was good. All the results of routine laboratory investigations were within normal limits.

Two and a half years earlier he had had an acute perforation of the appendix, and he had an appendicectomy at a regional hospital. The wound discharged for two months. Six months later he noticed abdominal swelling.

Abdominal ultrasound during his first admission showed massive, loculated ascites without enlargement or metastatic involvement of abdominal organs. Thoracic computed tomography showed thickened pleura and a homogeneous mass in the left hemithorax, described as "a dense pleural effusion" (fig 2). Abdominal computed tomography suggested "mucinous ascites," partly localised around the liver, following the intestinal curve and concentrated in the pelvis.

Pleural aspiration on several occasions disclosed no malignant cells but a few were found in one sample of pleural gelatinous material. A diagnosis of adenocarcinoma was confirmed by percutaneous biopsy of the main thoracic mass.

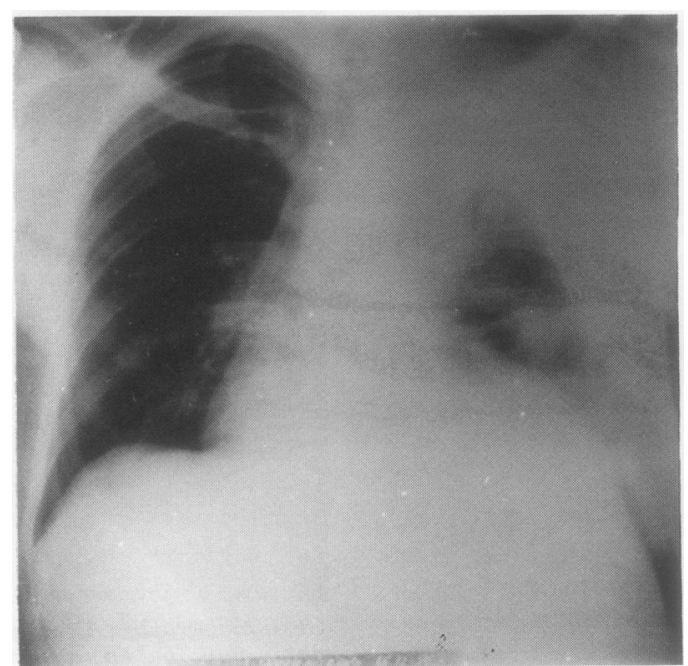

Figure 1 Posteroanterior chest radiograph:

homogeneous shadowing in the left hemithorax. 
Figure 2 Thoracic computed tomogram: dense pleural effusion.



Bronchoscopy showed no abnormality.

Owing to spread of adenocarcinoma within and beyond the abdomen, surgical treatment was not indicated and he was treated with three courses of doxorubicin (Adriamycin), vincristine, cyclophosphamide, and 5-fluorouracil, but these had little effect. Thereafter the patient remained in good general condition for several months, during which he was working, though he tired more easily after hard physical work.

From August 1989 his condition deteriorated, with increasing abdominal distension, umbilical and inguinal hernias, and progressive opacification in the left hemithorax with displacement of the mediastinum to the right. At that time the patient received further cytotoxic chemotherapy, corticosteroids, and intracavitary hyaluronidase (2000 IU) without any effect. Abdominal paracentesis evacuated only $500 \mathrm{ml}$ of a gelatinous substance. Finally he developed oedema of the lower limbs and eventually died in May 1991. Necropsy was not performed.

\section{Discussion}

Pseudomyxoma peritonei was first described in 1894 and there have been reports of a few cases since then. ${ }^{124}$ The gelatinous material is believed to be produced by a highly differentiated mucin producing adenocarcinoma of relatively low malignancy. Treatment of the abdominal condition has included the use of various anticancer drug combinations, hyaluronidase, corticosteroids, repeated palliative surgical treatment, postoperative radiotherapy, and simple conservative treatment. The survival of patients from the time of diagnosis is over $50 \%$ at five years and one patient has survived 24 years. ${ }^{124}$

The primary tumour in this case was probably in the appendix and the pleural lesion was due to metastatic spread. This has not been reported previously.

1 Limber KG, King ER, Silverberg GS. Pseudomyxoma peritonei. Ann Surg 1973;178:587-93.

2 Hughes John. Mucocele of the appendix with pseudomyxoma peritonei: a benign or malignant disease? $A n n$ Surg 1967;165:73-6.

3 Long TR, Spratt SJ, Dowling E. Pseudomyxoma peritonei. New concepts in management with a report of seventeen patients. Am J Surg 1969:117:162-9.

4 Fernandez R, Daly MJ. Pseudomyxoma peritonei. Arch Surg 1980;115:409-14.

\section{BOOK NOTICE}

Pulmonary function testing. 2nd ed. Reuben $M$ Cherniack. Pp 316; \$24.95, £15.95. USA: Harcourt Brace Jovanovich, 1992. ISBN 0-7216-4014-1.

This pocket size, spiral bound second edition contains a concise and informative account of basic pulmonary physiology and methods of assessing function. Although it has been revised and expanded since the 1977 version there has been little substantive change, revisions to the text and figures being overall of a cosmetic nature. This new edition has three sections, starting with basic pulmonary physiology, including lung mechanics, pulmonary ventilation and circulation, control of breathing, and adaptation to exercise. The second section describes a very extensive range of pulmonary function tests and how they may be used to measure the physiological variables introduced in the first section. Each test is described in mainly theoretical terms, though the section on provocation testing, which includes oral agents, deals with practical considerations, such as dosage and timing. The final section discusses interpretation of abnormal lung function and blood gas analysis in the context of the underlying pathophysiology. The book is well laid out with a large initial glossary and key to abbreviations and symbols used. Each section is completed by a fairly basic self assessment questionnaire with answers provided in an appendix. A second appendix includes normal values for the tests described in the text, although the choice of references is something of a mixed bag and presumably reflects the personal idiosyncrasy of the author. The book is very readable, brief, and to the point without omitting vital information. It does not provide sufficient detail for the expert but is an excellent starter for the lung function technician or perhaps the physician without a detailed physiological background who finds themself responsible for a local laboratory service.-CMR

\section{NOTICES}

\section{Pathology courses}

Three courses on pathology will be held in the spring at the National Heart and Lung Institute: (1) advanced cardiac pathology - the cardiac autopsy, interpreting the cardiac biopsy, recent advances in understanding the cardiomyopathies: 29 March 1993; (2) lung tumours - cell biology, cytology, pathology, radiology, staging, surgery, chemotherapy, radiotherapy, diagnosis, prognosis, genetics, oncogenes: 30-31 March 1993; (3) mediastinal tumours-pathology, radiology, diagnosis, thymomas, lymphomas, germ cell tumours, cysts, neural tumours, infections, surgery, chemotherapy: 1-2 April 1993.

For further details please contact Postgraduate Education Centre, National Heart and Lung Institute, London SW3 6LY (tel 071 351 8172; fax 071376 3442).

\section{Meeting on mycobacterial infections}

A joint meeting of the British Thoracic Society and the Association of Medical Microbiologists on mycobacterial infections will be held on 22 April 1993 at the Institute of British Architects, 66 Portland Place, London W1N 4AD. Details from Dr PDO Davies, Tuberculosis Research Unit, Sefton General Hospital, Liverpool L15 2HE (tel 051733 4020 ext 2062; fax 0517344641 ).

\section{Conference on Behçet's disease}

The sixth international conference on Behçet's disease will be held in Paris on 30 June and 1 July 1993 (deadline for abstracts $30 \mathrm{March}$ ). Details from Dr B Wechsler, Pitié-Salpêtrière Hôpital, 75013 Paris, Cédex 13 (fax 33 (1) 457063 53). 